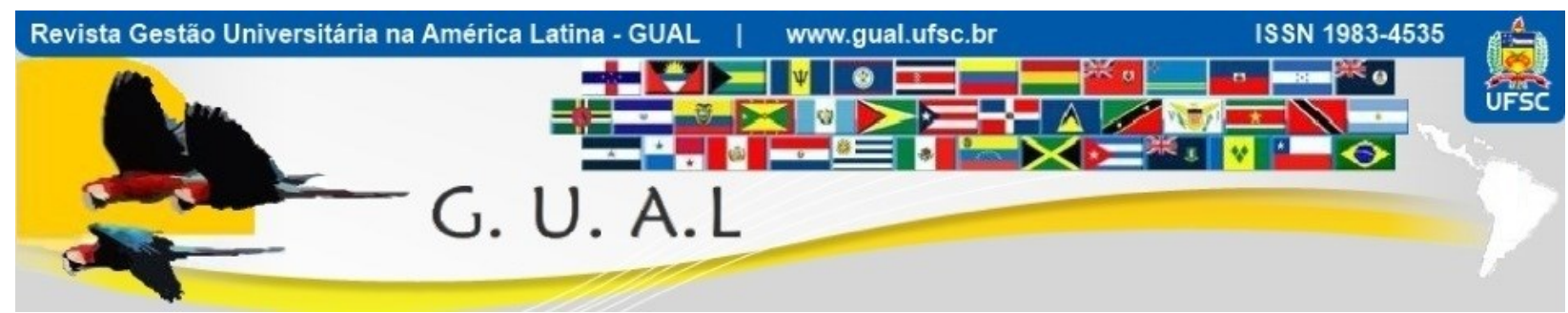

DOI: http://dx.doi.org/10.5007/1983-4535.2017v10n2p115

\title{
PLANEJAMENTO E GESTÃO ESTRATÉGICA NAS IES COMUNITÁRIAS
}

PLANNING AND STRATEGIC MANAGEMENT IN CITIZENSHIP UNIVERSITIES

Gissele Prette Heil, Especialista

Centro Universitário de Brusque - UNIFEBE gissele@unifebe.edu.br

Raul Otto Laux, Doutor Centro Universitário de Brusque - UNIFEBE raullaux@unifebe.edu.br

Recebido em 14/fevereiro/2016

Aprovado em 23/fevereiro/2017

Sistema de Avaliação: Double Blind Review

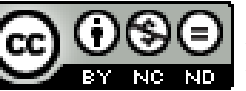

Esta obra está sob uma Licença Creative Commons Atribuição-Uso. 


\section{RESUMO}

Diante da complexidade da Gestão Universitária no âmbito Estadual e Nacional, destaca-se a importância de um Planejamento Estratégico bem elaborado, exequível e cujo desdobramento em ações, permite aos gestores atuarem em consonância com as exigências que se apresentam cotidianamente. $\mathrm{O}$ artigo tem como objetivo geral analisar como ocorre o processo de gestão estratégica nas Instituições Comunitárias do Sistema ACAFE. Os objetivos específicos foram divididos em quatro etapas, a primeira aborda a Estratégia, com o objetivo analisar o processo de estratégia organizacional, a segunda o Pensamento Estratégico com o intuito de identificar se possui indicadores da existência de pensamento estratégico, junto aos gestores, a terceira etapa destacará o Planejamento Estratégico, identificando se há e como é elaborado e a quarta etapa, considerando as etapas anteriores abordou-se as ações decorrentes da possível existência dos requisitos anteriores, bem como, se dá a formulação e implantação de ações e como são efetuados o monitoramento e o controle das estratégias. Entende-se que o tema abordado é de grande relevância, pois as Instituições Comunitárias de Ensino - ICES, possuem características genéricas e específicas o que acaba na maioria das vezes tornando o processo estratégico muito complexo, difícil e pouco efetivo. Cada vez mais as Instituições de Ensino Superior - IES, precisam formular suas estratégias adequando-as para atender as demandas latentes, desenvolvendo um processo de inteligência competitiva, permitindo lidar de modo mais eficaz com a concorrência, destacando o diferencial competitivo e atributos de valor percebidos pela comunidade onde está inserida. É de singular importância buscar a diferenciação, o destaque, a projeção necessária nos tempos atuais, para que possam sobreviver e crescer. Utilizou-se para a presente investigação o método de pesquisa exploratória, descritiva e qualitativa. Com o presente estudo analisou-se como ocorre o desenvolvimento do processo de gestão estratégica as ICES, permitindo inferir e identificar onde e como estão e para onde desejam e conseguem seguir.

Palavras-Chave: Planejamento estratégico. Estratégia. IES comunitárias. Empreendedorismo. Gestão Universitária. 


\begin{abstract}
Considering the complexity of University Management in the State and National levels, it is highlighted the importance of a well-designed and achievable Strategic Planning, whose actions allow the managers to act in accordance with the requirements that are presented on a daily basis. The article aims to analyze how the process of strategic management occurs in Citizenship Institutions of the ACAFE System.

The specific objectives were divided in four stages, the first one approaches the Strategy, with the objective to analyze the process of organizational strategy, the second is related to the Strategic Thinking in order to identify if it has indicators of the existence of strategic thinking, together with the managers, the third stage will highlight the Strategic Planning, identifying if it is present and how it is elaborated and the fourth step, considering the previous steps, takes into consideration the actions arising from the possible existence of the previous requirements, as well as, gives the formulation and implementation of actions and how the monitoring and strategies control are carried out.

It is understood that the topic addressed is of great relevance, since the Citizenship Institutions of Education, have generic and specific characteristics as well, which ends up in most cases making the strategic process very complex, difficult and not very effective. Increasingly, Higher Education Institutions need to formulate their strategies, adapting them to meet the latent demand, developing a process of competitive intelligence, allowing to deal more effectively with the competition, highlighting the competitive differential and value attributes perceived by the community where it is inserted.

It is important to seek differentiation, the prominence, the necessary projection in the present times, so that they can survive and grow. Exploratory, descriptive and qualitative research was used for the present study. This research analyzed how the strategic management process is developed in the Citizenship Universities, allowing to infer and to identify where and how they are and to where they want go and they are able to proceed.
\end{abstract}

Keywords: Strategic planning. Strategy. Citizenship universities. Entrepreneurship. University Management. 


\section{INTRODUÇÃO}

A temática principal desse artigo foi realizar um estudo acerca do processo de gestão estratégica nas Instituições Comunitárias que compõem o Sistema ACAFE - ICES.

O objetivo geral tem como foco analisar como ocorre o processo de gestão estratégica nas Instituições Comunitárias do Sistema ACAFE. Os objetivos específicos foram divididos em quatro etapas, a primeira aborda a Estratégia, com o intuito de analisar o processo de estratégia organizacional, a segunda o Pensamento Estratégico com o enfoque de identificar se possui indicadores da existência de pensamento estratégico, junto aos gestores, a terceira etapa destacará o Planejamento Estratégico, identificando se há e como é elaborado e a quarta etapa, considerando as etapas anteriores abordou-se as ações decorrentes da possível existência dos requisitos anteriores, bem como, se dá a formulação e implantação de ações e como são efetuados o monitoramento e o controle das estratégias.A metodologia utilizada foi a pesquisa exploratória, descritiva e qualitativa.

Os gestores têm papel fundamental nas Instituições para ampliar e estimular o desenvolvimento local e regional, para tanto, é necessário possuir o Pensamento Estratégico, que vai além do Planejamento Estratégico.

O Pensamento Estratégico é a intuição, ou seja, percepção de oportunidades para agregar ao planejamento estratégico. Por sua vez, a elaboração do planejamento é um norteador das ações/metas, que devem ser seguidos por todos da instituição, ressalta-se que a disseminação do planejamento é tão importante quanto a elaboração; pois, de nada adianta ter-se um excelente planejamento se os envolvidos não conseguem diagnosticar suas responsabilidades e comprometimento com o intuito de garantir o alinhamento dos objetivos, para que sejam alcançados com sucesso e com foco nos resultados.

Segundo Laux, (2013, p.89), “o pensamento estratégico é um dos lados de uma moeda, sendo o outro lado o planejamento estratégico.” Discute-se sobre estratégia como se esse termo não apresentasse ambiguidades, como se sua compreensão em sentido lato fosse compartilhada por todos os administradores universitários. $\mathrm{Na}$ verdade, o planejamento estratégico refere-se à programação sistemática das estratégias previamente identificadas e que compõem um plano de ação, o pensamento estratégico se constitui num processo de sintetização que utiliza a intuição e a criatividade, cujo resultado é uma perspectiva integrada da organização; e, ainda identificar qual a capacidade de antecipar o pensamento dos competidores. 
Nesse sentido, deve-se observar o ambiente interno e externo, pensando no que almeja-se a curto, médio e longo prazo, identificando-se as melhorias por meio dos indicadores para uma tomada de decisão assertiva.

\section{FUNDAMENTAÇÃO TEÓRICA}

Na Grécia antiga, a palavra estrategos, significava a arte do general, do juiz, do comandante e segundo diversos autores é a base da palavra estratégia. A Estratégia se desenvolveu na história da humanidade na base militar, sendo incorporada no meio empresarial logo após a II Guerra Mundial e no meio educacional, notadamente no Brasil, somente a partir do início dos anos 80 e, principalmente após os anos 90, quando iniciou a grande expansão do Ensino Superior no Brasil.

[...] a dificuldade em se administrar a universidade é antes de tudo um reflexo da dificuldade de administrar uma organização qualquer. Aqueles que a administram, baseados em teorias e modelos de gestão desconhecem que a própria empresa não é equilíbrio, mas desequilíbrio. Não é estabilidade, mas instabilidade. Não é harmonia, mas conflito. Não é simplicidade, mas complexidade. Logicamente, se há problemas de se entender essas questões nas empresas, haverá problemas também quando se aplicar os preceitos empresariais na universidade. Afinal, não é só a universidade que é complexa, conflituosa. Qualquer organização pode ser assim caracterizada. Pois as pessoas são complexas. E tanto as empresas quanto as universidades são constituídas por pessoas, administradas por pessoas. O que talvez torne a universidade "diferente" é que as complexidades pareçam mais evidentes nesta organização (SCHLICKMANN e MELO, p.2011).

Para tanto, cada vez mais os gestores necessitam ter conhecimento e clareza do pensamento estratégico para que consigam administrar as dificuldades e complexidades. E, tão importante quanto qual é a estratégia utilizada pela empresa, é entender como ocorre o processo de gestão estratégica nas empresas (MINTZBERG; QUINN, p.2001).

Sem entender como funciona o processo da gestão estratégica, fica-se vulnerável aos fatores internos e externos que afetam diretamente o processo de gestão. Segundo Zaccarelli (2005, p. 205), “a estratégia está relacionada diretamente com a vantagem competitiva, permitindo localizar o ponto mais vulnerável e protegê-lo, conhecendo as capacidades necessárias para o jogo da competição".

Percebe-se que as IES estão vivenciando uma nova realidade, por meio dos avanços tecnológicos e tendo uma nova ótica da real necessidade de utilizar e aprimorar os modelos de gestão para que possam alcançar seus objetivos.

De acordo com Costa (2004, p.54), a gestão estratégica pode ser descrita como "o processo sistemático, planejado, gerenciado, executado e acompanhado sob a liderança da alta 
administração da organização, e que visa envolver e comprometer todos os envolvidos, direta e indiretamente para o alcance dos objetivos propostos". Com uma gestão estratégica clara é mais fácil assegurar o desenvolvimento, dar continuidade e manter a IES sólida, com a constante revisão das estratégias, para que possam antecipar algumas mudanças provocadas pelos novos cenários externos. Almeida (2006, p.23), destaca:

\begin{abstract}
Apresenta-se como elemento crucial para o desenho de cenários futuros no ensino superior e abre espaço para uma nova arena que emerge de um conjunto de instituições dos tipos mais diversos com vistas a ocupar as janelas de oportunidades abertas resultantes da legalização de instituições de ensino superior com fins lucrativos, visando, sobretudo, atender a demanda mercadológica.
\end{abstract}

A concorrência entre as IES comunitárias e privadas é um grande desafio para sobreviver, pois sabe-se que as IES possuem características específicas. Enquanto as comunitárias muitas vezes estão engessadas por sua natureza jurídica para tomar algumas ações, as privadas estão apresentando grandes benefícios aos novos e potenciais alunos e com isso captando os mesmos, muitas vezes por valores de mensalidades atrativos, aulas em menos dias da semana, entre outros. Cunha (2011, p. 69), considera que:

Os desafios que se apresentam a gestão das universidades vão além do fato de terem
que acompanhar as mudanças e inovações do mundo globalizado. Sua lógica se
sustenta na estratégia de empresas e do Estado em torno de conhecimentos e
políticas governamentais na defesa de interesses da sociedade ou até mesmo do
capital.

Para que as IES encarem esses desafios é fundamental analisar e refletir sobre qual é o seu verdadeiro papel, isto é, repensar, redefinir e vislumbrar novas perspectivas, sem perder de vista a sua real finalidade.

O crescimento da instituição em número de cursos e serviços prestados em face da demanda; $\mathrm{O}$ crescimento institucional, com vários profissionais vindos de diferentes lugares e com formações adversas daquela que a instituição se esmerava em oferecer; $\mathrm{O}$ aumento de exigências dos órgãos Federais e Estaduais quanto às funções sociais serem desempenhadas pelas universidades; As dificuldades sempre crescentes quanto ao provimento de receitas pelo governo do estado para a manutenção das atividades institucionais; A sensibilidade de muitos atores dos vários segmentos institucionais (professores, funcionários técnico-administrativos alunos, dirigentes), os quais necessitam estar atentos aos cenários da globalização que se têm mostrado no horizonte (HANSEM, 2001, p. 285).

As IES precisam estar preparadas para enfrentar as adversidades que se prenunciarão no futuro, remodelando suas mudanças estruturais, pessoais e temporais, preservando sua essência e se integrando ao contexto atual de desenvolvimento. Por isso, a importância de todos conhecerem e estarem envolvidos nos processos de gestão da IES. Para que a gestão 
estratégica seja eficaz, é necessário que seja descentralizada, transparente, que pense nas pessoas e nos resultados, que esteja atenta às inovações e seja inteirada com a sociedade.

Enquanto muitas empresas e universidades discutem o Planejamento Estratégico - PE como orientação primordial para continuidade das mesmas percebe-se que o PE deveria ser precedido de um Pensamento Estratégico. "Pensar estrategicamente é uma metodologia da ação" - afirma Fabio Gallego ${ }^{1}$, complementando: - "a capacidade de gerar planos e de exercer controle sobre eles é uma das "super-habilidades» humanas que consiste na "capacidade estratégica» das pessoas para desenhar e executar planos”. Quando há um equilíbrio entre o pensamento estratégico e o PE, se é mais assertivos na construção do plano de ação.

\begin{abstract}
Há, efetivamente, necessidade de um pensamento: - que compreenda que o conhecimento das partes depende do conhecimento do todo e que o conhecimento do todo depende do conhecimento das partes; - que reconheça e examine os fenômenos multidimensionais, em vez de isolar, de maneira mutiladora, cada uma das suas dimensões; - que reconheça e trate as realidades, que são concomitantemente solidárias e conflituosas (como a própria democracia, sistema que se alimenta de antagonismos e ao mesmo tempo as regula); - que respeite a diferença, enquanto reconhece a unicidade. É preciso substituir um pensamento que se isola e separa por um pensamento que distingue e une. É preciso substituir um pensamento disjuntivo e redutor por um pensamento do complexo, no sentido originário do termo complexus: o que é tecido junto. (MORIN, 2007, p. 88-89).
\end{abstract}

O gestor com a mente mais aberta, com maior visão de médio e longo prazo, tem habilidades para pensar estrategicamente, alinhando os desafios do presente projetando o futuro.

\begin{abstract}
A exigida reforma do pensamento vai gerar um pensamento do contexto e do complexo. Vai gerar um pensamento que lida e enfrenta a incerteza. O pensamento que une substituirá a casualidade linear e unidirecional por uma casualidade em círculo e multirreferencial, corrigirá a rigidez da lógica clássica pelo diálogo capaz de conceber noções ao mesmo tempo complementares e antagonistas, e completará o conhecimento da integração das partes em um todo, pelo reconhecimento da integração do todo no interior das partes. (MORIN, 2007, p.92-93).
\end{abstract}

Tendo esta compreensão do pensamento e pensando estrategicamente, percebe-se que quanto mais diálogo melhor será a compreensão dos gestores. Morin (2007), destaca sete princípios para um pensamento que une: 1. O princípio sistêmico ou organizacional - é aquele que relaciona o conhecimento de uma parte com o todo, pois é impossível compreender o todo, sem conhecer cada parte; 2. O princípio "hologrâmico" - apresenta a contradição das organizações complexas, em que não apenas a parte está no todo, mas como o todo está inscrito na parte. 3. O princípio do circuito retroativo - neste princípio a causa age

\footnotetext{
${ }^{1}$ GALLEGO, Fabio. El pensamento estratégico. Barcelona: Ediciones Paidós Ibérica, 2004, p.14.
} 
sobre o efeito e o efeito age sobre a causa, ou seja, pode agir positivamente ou negativamente. O positivo seria o feedback e o negativo seria retroagir. 4. O princípio do circuito recursivo este destaca que as pessoas produzem a sociedade com as interações e pelas interações. 5. $O$ princípio da autonomia/dependência (auto-organização) - significa que os serem humanos não param de se auto-produzir para gerar sua autonomia. 6. O princípio diálogo - "permite assumir racionalmente a inseparabilidade de noções contraditórias para conceber um mesmo fenômeno complexo". 7. O princípio da reintrodução do conhecimento em todo conhecimento - destaca-se que a reforma do pensando é de natureza não programática, mas paradigmática, pois cada indivíduo organiza o seu conhecimento; precisa-se compreender que a clareza depende do modo como organizam-se as ideias. Assim, com base nesses princípios pode-se ter maior embasamento de como reformular o modo de pensar, sem perder de vista, a identidade, somente abrir a mente para que possa-se pensar estrategicamente.

Considerando o que afirma-se acima, todas as IES deveriam desenvolver Pensamento Estratégico como base de sua sobrevivência, entende-se que o PE nada mais é do que Pensamento Estratégico esquematizado, de acordo com método mais adequado, citamos Peter Drucker, grande estudioso do planejamento estratégico.

Planejamento estratégico é o processo contínuo de, sistematicamente e com maior conhecimento possível do futuro contido, tomar decisões atuais que envolvem riscos; organizar sistematicamente as atividades necessárias à execução dessas decisões e, através de uma retroalimentação organizada e sistemática, medir o resultado dessas decisões em confronto com as expectativas alimentadas. (DRUCKER, 1984, p.133).

Entende-se que o PE é o melhor processo para se atingir o desempenho institucional desejado. Para bem elaborar um PE deve-se observar o ambiente (interno e externo), analisar a estratégia por meio da missão, visão, objetivos e valores, formular as estratégias, implementá-las e controlá-las. Segundo Costa (2004, p.35) "ser o planejamento estratégico o princípio para uma organização definir um conjunto de elementos básicos que caracterizam aquilo que a organização gostaria de ser no futuro, bem como sua vontade e seu desejo de ser e agir”. Tendo essa clareza, é fácil definir os caminhos a trilhar para a construção do planejamento estratégico.

Como está a competitividade da organização? Como está o portfólio de produtos ou serviços? Como está a flexibilidade em relação as mudanças? Como está o grau de vulnerabilidade em relação as ameaças? Como esta a capacitação para construir as transformações necessárias? Como estão os recursos estratégicos? Estão assegurados? Por quanto tempo e em que quantidade e qualidade necessárias? Como estão os processos de desenvolvimento e inovação? Como está à estrutura de poder e de liderança? Como estão sendo tratados os temas e problemas críticos da 
organização? Existe um processo de projetar e construir o futuro da organização? Está implantado e é efetivo? (COSTA, 2004, p. 51).

Esses questionamentos auxiliam na tomada de decisão dos gestores, com o propósito de direcionar as ações, fortalecer os aspectos positivos e neutralizar os aspectos negativos. Born (2006, p.18), descreve que "o planejamento estratégico serve para gerar e integrar estratégias que traduzirão as intenções da organização no longo prazo, resultando num conjunto de ações responsáveis pela sua implementação". Seja uma organização ou uma IES, todas as organizações precisam agir de maneira estratégica, por isso que o planejamento estratégico tem sido uma importante ferramenta para sistematizar as ações e acrescentá-las ao objetivo maior da instituição, com eficiência, eficácia e efetividade. Para a elaboração de um PE adequado a realidade institucional é importante seguir alguns passos.

(1) Planejamento participativo: principal foco é o maior número de pessoas participantes para atingir o objetivo final. O papel do gestor não é simplesmente elaborá-lo, mas facilitar o processo de sua elaboração, disseminar e orientar as pessoas e as áreas pertinentes em cada etapa. (2) Planejamento coordenado: todos os aspectos envolvidos devem ser projetados interdependentes, com a finalidade de proporcionar maior flexibilidade e volatilidade no processo. (3) Planejamento integrado: os vários escalões de uma empresa devem ter seus planejamentos integrados. Geralmente os objetivos são escolhidos de "cima para baixo" e os meios de "baixo para cima". (4) Planejamento permanente: essa condição exigida pela própria turbulência empresarial, fatores internos e externos que propiciam necessidades extremas, pois, nenhum plano mantém seu valor com o tempo (OLIVEIRA, 2006, p. 42).

Quando o PE é elaborado em conjunto e disseminado, maior será sua eficiência, pois todos os colaboradores das IES, devem estar envolvidos no processo de construção, aplicação e monitoramento das ações, para que de fato o PE, tenha efetividade. Braga e Monteiro (2005, p. 150), destacam que “o planejamento estratégico é uma importante ferramenta que visa dotar as IES da capacidade de antecipar as novas mudanças e ajustar suas estratégias vigentes com a necessária velocidade e efetividade sempre que for preciso". Portanto, para o PE ser eficaz é necessário buscar maneiras para que os objetivos se concretizem, não somente descrever as ações. Para alcançar os objetivos devemos ter como princípio alguns pontos:

Definição das diretrizes estratégicas (missão, visão, valores); Análise ambiental (diagnóstico interno e externo); Definição dos objetivos estratégicos; Definição da metodologia aplicada; Construção do mapa estratégico; Levantamento de indicadores; Definição de metas (curto médio e longo prazo); Elaboração do plano de ação; Implementação da estratégia; Avaliação da estratégia; Controle estratégico. (BRAGA et al., 2005, p.210).

O PE quando elaborado a luz da missão institucional e pela visão, com certeza será mais eficaz, pois quando se parte da razão de ser e do que se pretende ser e alcançar no futuro, 
já se possui uma diretriz. Se construído sem a análise dos ambientes e dos cenários, o PE torna-se frágil.

O grande desafio de implantar uma gestão estratégica numa IES está nas dificuldades de ordem cultural, acadêmica e administrativa, onde há grandes desafios em dar uma visão estratégica e integrar as áreas de ensino, pesquisa e extensão para tornar suas atividades mais eficientes, eficazes e efetivas. (MARCELINO, 2004, p.32).

Desta forma, o PE quando interpretado como ferramenta de gestão contribui e auxilia os gestores nas tomadas de decisões, direcionando resultados a curto, médio e a longo prazo.

Nesse sentido, as ações decorrentes da Estratégia, do Pensamento Estratégico e do PE, devem ser recorrentes e incentivadas. Born (2006), destaca que:

O planejamento estratégico serve para gerar e integrar estratégias que traduzirão as intenções da organização no longo prazo, resultando num conjunto de ações responsáveis pela sua implementação.

Os objetivos quando bem definidos e claros a partir do PE, são um dos principais mecanismos para tornar mais estratégicas as ações a longo prazo, minimizando os possíveis riscos oriundos dos ambientes (interno e externo), alertando os gestores para novas práticas e tecnologias.

O PE deve ser integrado ao Plano de Desenvolvimento Institucional - PDI, para que todos os segmentos da IES, sigam o mesmo rumo, a interação e o envolvimentos de todos faz a grande diferença na prática das ações, no monitoramento e no controle das mesmas. Hansen (2001, p. 285), afirma que "os principais desafios das universidades são os seguintes: repensar o seu papel; redefinir os seus rumos; vislumbrar novas perspectivas que se lhes apresentam na sociedade; e resgatar a sua identidade". Para enfrentar os desafios, as IES devem focar em ações que nunca percam a sua origem e finalidade. Drucker $(1984$, p.131) destaca que "o planejamento não diz respeito à decisões futuras, mas às implicações futuras das decisões presentes".

\section{METODOLOGIA}

A pesquisa tem por finalidade, quando bem aplicada e analisada obter dados que propicie um diagnóstico sobre o processo de gestão estratégica das Universidades Comunitárias do Sistema ACAFE e possibilitar a tomada de ações que visem à melhoria.

O estudo realizado foi do tipo dissertativo, segundo Martins e Lintz (200, p.36), “é o estudo de uma unidade que analisa profunda e intensamente. Considera a unidade social 
estudada em sua totalidade, seja um indivíduo, uma família, uma instituição, uma empresa, ou uma comunidade, com o objetivo de compreendê-los em seus próprios termos".

Nessa investigação, analisou-se como ocorre o processo de gestão estratégica nas Universidades Comunitárias do Sistema ACAFE.

Os enfoques usados na investigação e na coleta de dados é o qualitativo, permitindo assim, a comparação da realidade investigada com os fundamentos teóricos estudados. De acordo com Marconi e Lakatos (1986, p.57), "ao considerar os diferentes pontos de vista dos participantes, os estudos qualitativos permitem iluminar o dinamismo interno das situações, geralmente inacessível ao observador externo".

O tipo de pesquisa apresentada foi realizado por meio de um questionário on line. Segundo Matar (1996, p.85), "são caracterizadas por possuírem objetivos bem definidos, procedimentos formais, serem bem estruturadas e dirigidas para a solução dos problemas ou avaliação de alternativas de curso de ação".

Os sujeitos do estudo foram os Reitores que compõem a Associação Catarinense das Fundações Educacionais - ACAFE.

Foram encaminhados 16 questionários por meio do software e ferramenta de pesquisa "survey monkey" e obteve-se o retorno de 11 respostas, num período aproximado de trinta dias, entre outubro e novembro de 2016.

Segundo Rizzini, Castro e Sartor (1999, p.24), “o rigor e a objetividade estão diretamente relacionados com a coerência entre o que o pesquisador se dispõe a fazer e o que realmente faz, entre as perguntas que ele se dispõe a responder e as que efetivamente responde".

Com esse intuito, optou-se pelo uso do questionário como instrumento de coleta de dados, tendo em vista a maior praticidade, agilidade para tabulação dos dados obtidos.

\section{RESULTADOS DA PESQUISA}

Apresenta-se a análise dos dados coletados por meio das respostas dos questionários respondidos pelo Reitores, com vistas ao alinhamento as objetivos específicos.

Visualiza-se, na tabela 1, a frequência da revisão do Planejamento Estratégico nas ICES. 
Tabela 1 Considerando que sua Instituição possui Planejamento Estratégico, com que frequência ele é revisado?

\begin{tabular}{llr}
\hline Opções de resposta & Respostas (\%) & Respostas \\
\hline A cada 3 meses & $0,00 \%$ & 0 \\
A cada 6 meses & $18,18 \%$ & 2 \\
A cada 12 meses & $54,55 \%$ & 6 \\
Outro (especifique) & $27,27 \%$ & 3 \\
Total & & 11 \\
\hline
\end{tabular}

Fonte: Elaborado pelos autores, 2016.

Evidenciou-se que 6 dos 11 respondentes revisam o Planejamento Estratégico a cada doze meses; 3 responderam na opção Outro (o ciclo do Planejamento é de cinco anos e revisado a cada dozes meses; o Planejamento está paralisado; está em fase de elaboração e implantação) e 2 afirmam que é revisado a cada seis meses.

Nesse sentido, percebeu-se que as IES respondentes estão preocupadas com a revisão e com o desenvolvimento do Planejamento Estratégico, para bem realizar as ações e demonstrar seu diferencial competitivo.

Observa-se, na tabela 2, a área responsável pela elaboração e Planejamento Estratégico.

Tabela 2 Qual a área responsável pela elaboração e disseminação do Planejamento Estratégico na sua IES?

\begin{tabular}{llr}
\hline Opções de resposta & Respostas (\%) & Respostas \\
\hline Reitoria & $18,18 \%$ & 2 \\
Pró-Reitoria de Planejamento & $18,18 \%$ & 2 \\
Consultoria externa & $9,09 \%$ & 1 \\
Consultoria interna & $9,09 \%$ & 1 \\
Outro (especifique) & $45,45 \%$ & 5 \\
Total & & 11 \\
\hline
\end{tabular}

Fonte: Elaborado pelos autores, 2016.

Identificou-se que 5 respondentes apontam a opção Outro, as respostas foram as seguintes: (O Planejamento Estratégico está vinculado: a Vice Reitoria; Gestão Estratégica; Vice Reitoria de Planejamento e Desenvolvimento Institucional; Diretor Executivo em conjunto com o Gerente Administrativo de campus, uma Assessora técnica e Setor de Planejamento Institucional), 2 destacam que os responsáveis são Reitoria e Pró-Reitoria de Planejamento e 1 é realizado por consultoria interna e externa.

Destaca-se que poucas IES, têm a elaboração e disseminação do Planejamento Estratégico, vinculado a maior hierarquia, pois cada IES possui características peculiares. Nesse sentido, entende-se que dependendo da forma como o líder do processo de Planejamento Estratégico conduz esse trabalho, nem sempre poderá ser eficaz, pois os 
conceitos de Pensamento e Planejamento Estratégico, devem ser muito bem alinhados com gestor de maior hierárquico.

Apresenta-se, na tabela 3, o grau de importância das Ações Estratégicas, Pensamento Estratégico e Planejamento Estratégico.

Tabela 3 Classifique o grau de importância dos itens abaixo, segundo sua experiência como gestor. Sendo que 3 é para o mais importante e 1 para o menos importante.

\begin{tabular}{|c|c|c|c|c|c|}
\hline \multirow{2}{*}{ Opções de Respostas } & \multicolumn{5}{|c|}{ Respostas } \\
\hline & 1 & 2 & 3 & Total & Pontos \\
\hline \multirow{2}{*}{ Ações Estratégicas } & $40,00 \%$ & $20,00 \%$ & $40,00 \%$ & \multirow[b]{2}{*}{10} & \multirow[b]{2}{*}{4,70} \\
\hline & 4 & 2 & 4 & & \\
\hline \multirow{2}{*}{ Pensamento Estratégico } & $54,55 \%$ & $36,36 \%$ & $9,09 \%$ & \multirow{3}{*}{11} & \multirow[b]{2}{*}{5,18} \\
\hline & 6 & 4 & 1 & & \\
\hline \multirow{2}{*}{ Planejamento Estratégico } & $0,00 \%$ & $45,45 \%$ & $54,55 \%$ & & \\
\hline & 0 & 5 & 6 & 11 & 4,18 \\
\hline
\end{tabular}

Fonte: Elaborado pelos autores, 2016.

Observou-se que 6 das 11 IES respondentes, classificam o Pensamento Estratégico como o grau mais importante; 5 apontam o Planejamento Estratégico e 4 as Ações Estratégicas.

Vale ressaltar que para a excelência do Planejamento Estratégico, o Pensamento Estratégico nos gestores deve envolver intuição, criatividade, para bem planejar, analisar e formalizar as etapas do processo.

Visualiza-se, na tabela 4, os principais indicadores para a verificação dos Resultados no Planejamento Estratégico.

Tabela 4 Identifique quais dos indicadores abaixo são utilizados em sua IES para verificação dos resultados estabelecidos no Planejamento Estratégico:

\begin{tabular}{llr}
\hline Opções de resposta & Respostas (\%) & Respostas \\
\hline Infraestrutura & $90,91 \%$ & 10 \\
Novos Cursos de Graduação & $81,82 \%$ & 9 \\
Novos Cursos de Especialização & $63,64 \%$ & 7 \\
Novos Cursos de Mestrado e Doutorado & $54,55 \%$ & 6 \\
Novos Cursos de Extensão & $45,45 \%$ & 5 \\
Internacionalização & $54,55 \%$ & 6 \\
Sustentabilidade Financeira & $100,00 \%$ & 11 \\
Processos de Qualidade & $63,64 \%$ & 7 \\
Sustentabilidade & $63,64 \%$ & 7 \\
Talentos Humanos & $54,55 \%$ & 6 \\
Aumento da capilaridade da oferta de cursos via EaD & $45,45 \%$ & 5 \\
Tecnologia adotada & $27,27 \%$ & 3 \\
Inadimplência & $72,73 \%$ & 8 \\
Evasão & $90,91 \%$ & 10 \\
Quantidade de Acadêmicos & $90,91 \%$ & 10 \\
Outro (especifique) & $18,18 \%$ & 2 \\
Total & & 11 \\
\hline
\end{tabular}

Fonte: Elaborado pelos autores, 2016. 
Os indicadores utilizados na tabela acima estão vinculados aos índices de performance do MEC/CAPES, referentes as políticas de graduação e políticas de pós-graduação.

Observou-se que 11 respondentes utilizam a Sustentabilidade Financeira como indicador; 10 destacam a Infraestrutura, a Evasão e a Quantidade de Acadêmicos; 9 apontam Novos Cursos de Graduação; 8 evidenciam a Inadimplência; 7 considera Novos Cursos de Especialização, Processos de Qualidade e Sustentabilidade; 6 destaca Novos Cursos de Mestrado e Doutorado, Internacionalização e Talentos Humanos, 5 Novos Cursos de Extensão e Aumento da capacidade da oferta de cursos via EaD; 3 consideram a Tecnologia Adotada e 2 responderam em Outros (Titulação docente, ações de responsabilidade social, equilíbrio financeiro, desempenho IGC Mec, Projetos de pesquisa, publicações docentes, docentes envolvidos em pesquisa, capacitação docente e técnico-administrativo, desenvolvimento de material didático, operacionalização dos setores, desempenho em provas da OAB e CRC, aplicação do orçamento, visibilidade da marca, meios de acesso, relação com egresso, entre outros; Ociosidade, produção científica dos professores, titulação docente e dos técnicos funcionários, capacitação docente e dos técnicos continuada, resultado financeiro por curso e programas, avaliação de custos).

Os indicadores são fundamentais para auxiliar o gestor, facilitando o planejamento e o controle do desempenho, possibilitando a análise comparativa, o desdobramento de novas metas e contribuindo de forma assertiva para a melhoria contínua dos processos.

Observa-se, na tabela 5, a importância do ciclo de melhoria contínua nas organizações.

Tabela 5 Considerando que os autores destacam o ciclo de melhoria contínua para distintas organizações, classifique os itens abaixo em ordem de importância. Sendo que o 4 tem maior prioridade e o 1 menor.

\begin{tabular}{|c|c|c|c|c|c|c|}
\hline \multirow{2}{*}{ Opções de Respostas } & \multicolumn{6}{|c|}{ Respostas } \\
\hline & 1 & 2 & 3 & 4 & Total & Pontuação \\
\hline \multirow{2}{*}{ Realizar Ações } & $0,00 \%$ & $36,36 \%$ & $18,18 \%$ & $45,45 \%$ & 11 & 1,91 \\
\hline & 0 & 4 & 2 & 5 & & \\
\hline \multirow{2}{*}{ Comparar Resultados } & $63,64 \%$ & $27,27 \%$ & $9,09 \%$ & $0,00 \%$ & 11 & 3,55 \\
\hline & 7 & 3 & 1 & 0 & & \\
\hline \multirow{2}{*}{ Medir Desempenho } & $9,09 \%$ & $18,18 \%$ & $45,45 \%$ & $27,27 \%$ & 11 & 2,09 \\
\hline & 1 & 2 & 5 & 3 & & \\
\hline \multirow{2}{*}{ Identificar Melhorias } & $27,27 \%$ & $18,18 \%$ & $27,27 \%$ & $27,27 \%$ & 11 & 2,45 \\
\hline & 3 & 2 & 3 & 3 & & \\
\hline
\end{tabular}

Fonte: Elaborado pelos autores, 2016.

O foco do Ciclo PDCA, abrange os seguintes elementos $\mathrm{P}=$ Plan (Planejamento), $\mathrm{D}=$ Do (Fazer, execução), $C$ = Check (Checagem, verificação) e $A=$ Act (Ação), que também é 
denominado Ciclo de Melhoria Contínua. Este ciclo não possui um fim obrigatório, ele é contínuo (PACHECO et al, 2016).

Assim sendo, identificou-se que 7 das 11 IES destacam que Comparar Resultados é o item mais importante do ciclo de melhoria contínua; 5 afirmam ser a Realizar Ações e Medir Desempenho; 4 Realizar ações; 3 apontam Comparar Resultados, Medir Desempenho, Identificar Melhorias e 1 Medir Melhorias.

Quando possui-se indicadores, pode-se conhecer e medir o desempenho, comparar os resultados, identificar em que se pode melhorar e propor ações transformadoras, proporcionando um ciclo de melhoria Contínua.

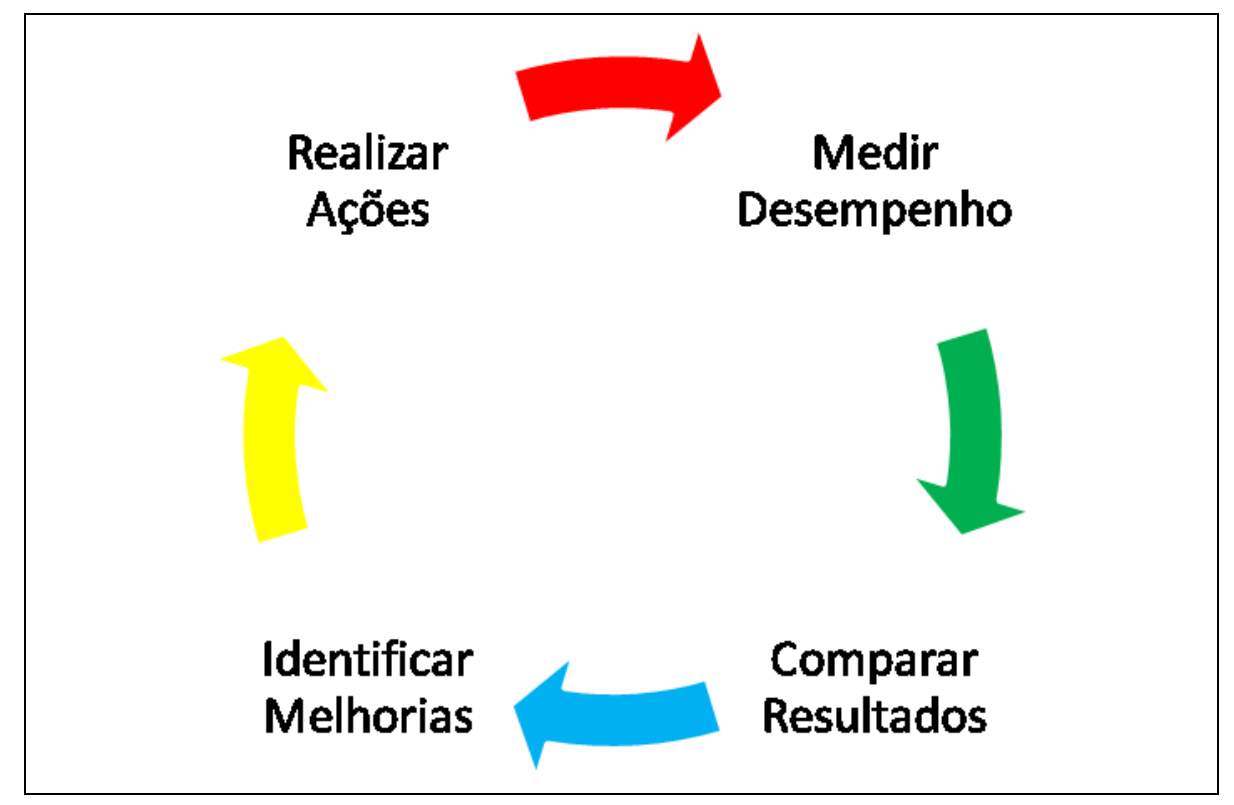

Figura 1 Ciclo de Melhoria Contínua.

Fonte: Elaborado pelos autores, 2016.

Com esses elementos, facilita-se o processo de tomada de decisão.

Identifica-se, na tabela 6, como ocorre o processo estratégico nas ICES.

Tabela 6 Identifique como ocorre o processo estratégico em sua IES:

\begin{tabular}{llr}
\hline Opções de resposta & Respostas (\%) & Respostas \\
\hline $\begin{array}{l}\text { Necessidade identificada pela Reitoria, considerando análise do ambiente } \\
\text { interno }\end{array}$ & $54,55 \%$ & 6 \\
Necessidade identificada pela Reitoria, considerando análise do ambiente & $54,55 \%$ & 6 \\
externo & & \\
Processo de Inteligência Competitiva & $90,91 \%$ & 10 \\
Disseminação da Cultura Estratégica & $45,45 \%$ & 5 \\
Benchmarking & $27,27 \%$ & 3 \\
Outro (especifique) & $18,18 \%$ & 2 \\
Total de respondentes: & & 11 \\
\hline
\end{tabular}

Fonte: Elaborado pelos autores, 2016. 
Observou-se que 10 afirmam que o processo estratégico se dá pelo Processo de Inteligência Competitiva; 6 destacam a Necessidade identificada pela Reitoria, considerando a análise do ambiente interno e externo; 5 aponta para a Disseminação da cultura estratégica; 3 define o Benchmarking e 2 responderam em Outros (Necessidade identificada pela áreas (Centros) e Vice Reitorias com análise do ambiente externo e planejamento por setores e cursos e níveis hierárquicos a partir de indicadores e metas estabelecidos para cada um).

O processo do planejamento estratégico é imprescindível para o desenvolvimento da IES, pois a necessidade de inovação é constante, entende-se que o sucesso de sua execução depende do modo como é disseminado.

O líder só será capaz de seduzir sua equipe e alcançar os objetivos institucionais, se de fato compreender e vivenciar a essência do Pensamento e do Planejamento Estratégico.

\subsection{SISTEMA ACAFE}

A Associação Catarinense das Fundações Educacionais - ACAFE, é composta por 16 Instituições Comunitárias de Educação Superior - ICES, conforme a Lei $n^{\circ} 12.881 / 13$, de 12/11/13, de direito privado, sem finalidade lucrativa, sendo 11 Universidades e 05 Centros Universitários.

A ACAFE tem como Missão "Desenvolver o ensino, ciência, tecnologia e inovação pelo compartilhamento de ações e competências para assegurar o fortalecimento das IES associadas em prol da educação superior em Santa Catarina". E sua Visão: "Ser reconhecido Nacional e Internacionalmente como um Sistema de Educação Superior integrado e sinérgico, capaz de produzir resultados para as IES e para a Sociedade na produção do conhecimento, da ciência, da tecnologia e da inovação”.

Nesse sentido, na busca do desenvolvimento das microrregiões do estado de Santa Catarina, as IES filiadas à ACAFE, cumprem sua função social, desenvolvem, sem ônus para os beneficiários, programas e projetos de assistência à comunidade, contribuindo para a melhoria da qualidade de vida, inclusão social e construção da cidadania.

\section{CONCLUSÕES}

É possível o Pensamento Estratégico estar desvinculado do Planejamento Estratégico? A resposta deveria ser simples, pois ambos são elementos essenciais para a gestão estratégica e precisam estar diretamente vinculados, pois se complementam e devem estar relacionados para beneficiar o processo decisório na Gestão Universitária. 
Uma Instituição de alto desempenho é aquela que está sempre em constante mudança e seu aprendizado é consequência do modelo de gestão estratégica.

O foco na inovação, desencadeia um processo de constante renovação, atendendo os anseios da alta administração, corpo docente, corpo técnico-administrativo e seu público alvo.

O processo do planejamento estratégico é de aprendizado constante, no qual destacamos que alguns de seus elementos são: Inovação, Flexibilidade, Interação, Reflexão e Foco no mercado.

A presente pesquisa oportunizou identificar através das respostas dos gestores, o atual estágio das inquietudes vinculadas a Gestão Universitária das ICES, que compõem a amostra, suas percepções, a importância do Planejamento Estratégico e sua revisão, os responsáveis e o processo de disseminação do Planejamento Estratégico, o grau de importância dos indicadores utilizados, o ciclo de melhoria contínua e como ocorre o processo estratégico.

Percebe-se que ainda existem muitas lacunas na compreensão e na cultura do Pensamento Estratégico e Planejamento Estratégico, o que abarca um grande desafio para os gestores das Universidades: desmistificar as complexidades e agir pro-ativamente focado na sustentabilidade das nossas Instituições Comunitárias.

Considera-se ser imprescindível os gestores entenderem, compreenderem e refletirem sobre a seguinte sequência lógica, dinâmica e estratégica para o presente e futuro das ICES: pensamento estratégico, planejamento estratégico e ações estratégicas, afinal existir hoje, será muito diferente de sobreviver amanhã.

\section{REFERÊNCIAS}

ALMEIDA, Márcio. A universidade possível: experiências de gestão universitária. São Paulo: Cultura, 2011.

BERNARDES, M. E. B.; DIAS, C. G.; DRUMMONG, A. Processo de Implantação de Estratégia: Onde Estamos e Como Podemos Prosseguir. In: XXXII Encontro Nacional dos Programas de Pós-Graduação em Administração - EnANPAD, 2008, Rio de Janeiro. Anais... Anpad, 2008.

BEVILACQUA, Luiz; et al. (Re)pensando a universidade: autonomia. Rio de Janeiro: UFRJ/COPEA, 2004.

BORN, Roger. Desvendando o planejamento estratégico. Porto Alegre: Sulina, 2006.

BRAGA, Ryon; MONTEIRO, Carlos. Planejamento estratégico sistêmico para instituições de ensino. São Paulo: Hoper, 2005. 
CORREAA, A. C. O Balanced Scorecard como um Sistema Adaptativo Complexo: uma abordagem quântica à estratégia. 2005. 360p. Tese de Doutorado. Programa de Pósgraduação em Engenharia de Produção e Sistemas, Universidade Federal de Santa Catarina, Florianópolis, 2005. Disponível em: http://teses.eps.ufsc.br/defesa/pdf/8758.pdf.

COSTA, Eliezer Arantes da. Gestão estratégica. São Paulo: Saraiva, 2004.

Gestão estratégica: da empresa que temos a empresa que queremos. 2. ed. São Paulo: Saraiva 2007.

CUNHA, M.R. Gestão Estratégica de IES: modelos e funções do planejamento estratégico em universidades públicas e privadas de Palmas - Tocantins. Dissertação de mestrado pela Universidade Lusófona de Humanidades e Tecnologias, Lisboa, 2001.

DRUCKER, P. Introdução à administração. São Paulo: Pioneira, 1984.

FERREIRA, M. V. A. S. Planejamento estratégico: uma ferramenta efetiva para a gestão de IES comunitária. Florianópolis, 2006. 132p. Dissertação (Mestrado Executivo em Administração) - Programa de Mestrado Executivo em Administração, Unisul Florianópolis, 2006.

GALLEGO, Fabio. El pensamento estratégico. Barcelona: Ediciones Paidós Ibérica, 2004. GIL, Antônio Carlos. Como elaborar projetos de pesquisa. 3 ed. São Paulo: Atlas, 1996.

HANSEN, Gilvan Luiz. Limites e potenciais das novas modalidades de gestão universitária. São Paulo: Cultura, 2001.

HITT, M. A.; IRELAND, R. D.; HOSKISSON, R. E. Administração Estratégica. 2. ed. São Paulo: Thomson, 2008

KAPLAN, R. S.; NORTON D. P. The office of Strategy Management. Harvard Business Review, v. 83, n. 10, p. 72-80, 2005.

Organização Orientada para a Estratégia. Campus. Rio de Janeiro, 2000.

Mapas Estratégicos. Campus. Rio de Janeiro, 2000.

LAUX, Raul Otto. Plan de gestión estratégico como herramienta para auto-sustentabilidad de universidades brasileiras: el contexto de Santa Catarina (Brasil). UNaM, Argentina, 2013.

LUECKE, Richard. Estratégia: criar e implementar a melhor estratégia para o seu negócio.

Harvard Business Essentials. Rio de Janeiro: Record, 2008.

MAINARDES, E. W.; FERREIRA, J. J. M.; TONTINI, G. O entendimento do conceito de estratégia e de gestão estratégica dos formandos em Administração. Revista Angrad, v. 10, n. 4 , p. 55-82, 2009. 
MARCELINO, Gileno Fernandes (Org.). Gestão estratégica de universidade: a construção da FACE/UnB. Brasília: Universidade de Brasília, 2004.

MARCONI, Marina de Andrade, LAKATOS, Eva Maria. Técnicas de pesquisa. São Paulo: Atlas, 1986.

MARTINS, Gilberto de Andrade; LINTZ, Alexandre. Guia para elaboração de monografias e trabalhos de conclusão de curso. São Paulo: Atlas, 2000.

MATTAR, F. N. Pesquisa de marketing. 2. ed. São Paulo: Atlas, 1996.

MELO, Pedro Antônio et al. A gestão universitária em debate. Florianópolis: Insular, 2000.

MINTZBERG, H; QUINN, JB. O Processo da Estratégia. Porto Alegre: Bookmann, 2001.

MORIN, Edgar. A cabeça bem feita: repensar a reforma, reformar o pensamento. 13. ed. Rio de Janeiro: Bertrand, 2007.

OLIVEIRA, Djalma de Pinho de Rebouças de. Planejamento estratégico: conceitos, metodologias e práticas. 22 ed. São Paulo: Atlas, 2006.

PACHECO, Ana Paula Reusing; SALLES, Bertholdo Werner; GARCIA, Marcos Antônio; POSSAMAI, Osmar. O ciclo PDCA na gestão do conhecimento: Uma abordagem sistêmica. Universidade federal de Santa Catarina, Florianópolis: SD. Disponível em: http:// http://isssbrasil.usp.br/artigos/ana.pdf, acesso em 25 de novembro de 2016.

PORTER, Michael E. Estratégia competitiva. Rio de Janeiro: Elsevier, 2004.

REBELO, L.M.B.; ERDMANN, R.H. Modelo de formação de estratégias de gestão em Instituições de ensino superior sob o enfoque da teoria da complexidade. Revista de Administração e Inovação, v. 4, n. 1, p. 05-20, 2007.

RIZZINI, Irma; CASTRO, Mônica Rebello de; SARTOR, Carla Daniel. Pesquisando: guia de metodologia da pesquisa para programas sociais. Rio de Janeiro: Ed. Universitária Santa Ursula, 1999.

SANTOS, Boaventura de Souza. A universidade do século XXI. 2. ed. São Paulo: Cortez, 2005.

SCHLICKMANN, Raphael; MELO, Pedro Antônio de. Administração Universitária: Em busca de uma Epistemologia. Revista da Avaliação da Educação Superior. Sorocaba, v.17, n. 1,2012

WHITTINGTON, R. O que é estratégia? São Paulo: Thomson Learning, 2006

ZACARELLI, Sérgio B. Estratégia e Sucesso nas Empresas. $5^{\text {a }}$ ed. São Paulo: Saraiva, 2005. 